\title{
OPEN A genetic screen for Drosophila social isolation mutants and analysis of sex pistol
}

\begin{abstract}
Mark Eddison
Prolonged periods of forced social isolation is detrimental to well-being, yet we know little about which genes regulate susceptibility to its effects. In the fruit fly, Drosophila melanogaster, social isolation induces stark changes in behavior including increased aggression, locomotor activity, and resistance to ethanol sedation. To identify genes regulating sensitivity to isolation, I screened a collection of sixteen hundred P-element insertion lines for mutants with abnormal levels of all three isolation-induced behaviors. The screen identified three mutants whose affected genes are likely central to regulating the effects of isolation in flies. One mutant, sex pistol (sxp), became extremely aggressive and resistant to ethanol sedation when socially isolated. sxp also had a high level of male-male courtship. The mutation in sxp reduced the expression of two minor isoforms of the actin regulator hts (adducin), as well as mildly reducing expression of CalpA, a calcium-dependent protease. As a consequence, sxp also had increased expression of the insulin-like peptide, dILP5. Analysis of the social behavior of sxp suggests that these minor hts isoforms function to limit isolation-induced aggression, while chronically high levels of dILP5 increase male-male courtship.
\end{abstract}

Being forcefully deprived of social contact can profoundly alter behavior, negatively impacting somatic and psychiatric health. In fact, objective social isolation and subjective, or perceived, social isolation (i.e. 'feeling lonely') is as a significant risk factor for morbidity and mortality as alcoholism, smoking, obesity and high blood pressure $^{1,2}$. Further, the lack of meaningful social relationships is considered a major contributor in the etiology of several psychiatric disorders ${ }^{3}$. Symptoms of social isolation can include heightened anxiety, anger and depression, cognitive rigidity, impaired sleep, increased drug use and a compromised immune response $\mathrm{e}^{4}$. Individuals differ in their response to social isolation and it is estimated that heritability accounts for approximately $50 \%$ of these differences ${ }^{5,6}$. Yet despite the fact that social isolation is increasing in society ${ }^{7}$, especially during these times ${ }^{8}$, we are only beginning to identify which genes regulate susceptibility to its effects ${ }^{6,9}$.

Like humans, most animals are also negatively impacted by forced social isolation. In rodents, social isolation increases measures of anxiety, aggression and cognitive deficits, that vary according to the age at the time of isolation and length of being socially deprived ${ }^{10,11}$. Social isolation in rodents also increases alcohol consumption ${ }^{12}$ and other drug-associated behaviors ${ }^{13}$. Such changes in behavior are likely due to differences in neurogenesis ${ }^{14}$, epigenetics $^{15}$, gene expression ${ }^{16}$, phosphorylation ${ }^{17}$, neuronal morphology ${ }^{10}$, physiology $^{18}$ and neuroendocrine secretion ${ }^{19}$ in isolated individuals. Importantly, social isolation in rodents has been used to model anxiety and depressive disorders ${ }^{20}$, schizophrenia ${ }^{21}$ and drug abuse ${ }^{13}$; diseases that in common have dysregulated emotion and associated behaviors. Isolation also has a profound effect on the behavior of the fruit fly, Drosophila melanogaster. Isolated males have increased aggression ${ }^{22,23}$, social interactions ${ }^{24}$, daytime locomotion ${ }^{25,26}$ and resistance to ethanol sedation ${ }^{27}$, while courtship duration and grooming are decreased ${ }^{24,28}$. Like mammals, differences have been documented in the neuronal morphology $y^{29-31}$, gene expression ${ }^{23}$, epigenetics ${ }^{32}$ and physiology ${ }^{33}$ of isolated flies, raising the possibility of conserved mechanisms that act to alter behavior in response to being isolated.

Here I describe a forward genetic screen aimed to identify candidate genes central to the regulation of isolation-induced behaviors, such as the recently described role of the Tac 2 neuropeptide in mice ${ }^{34}$. The screen identified three mutations and candidate genes that affected isolation-induced changes in aggression, locomotor activity and ethanol resistance. Importantly, all three behaviors were normal when the mutants were socially housed, suggesting the candidate genes specifically mediate effects of isolation. Here, I describe an in-depth analysis of one mutant, sex-pistol ( $x x p$ ), demonstrating that its mutation affects at least two genes that separably regulate the level of male-male aggression and male-male courtship. 
A

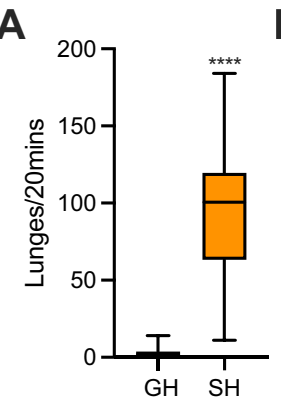

B

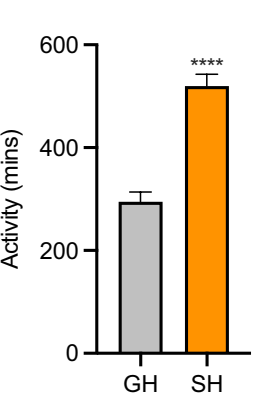

C

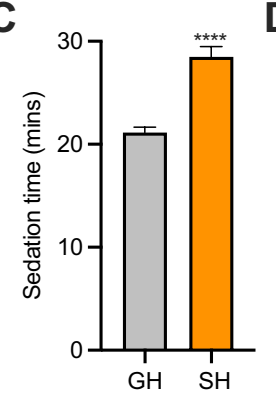

D $\begin{gathered}\text { Hypo- } \\ \text { aggressive }\end{gathered}$

\begin{tabular}{l|l}
28 & Norm \\
28 &
\end{tabular}

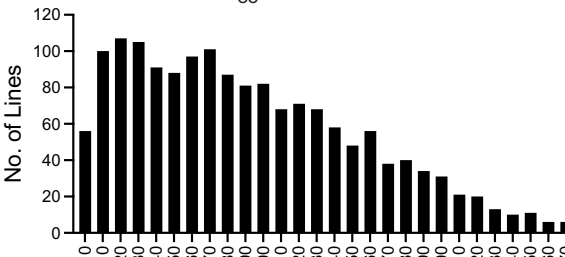

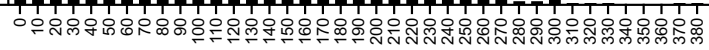

Mean SH Lunges

E

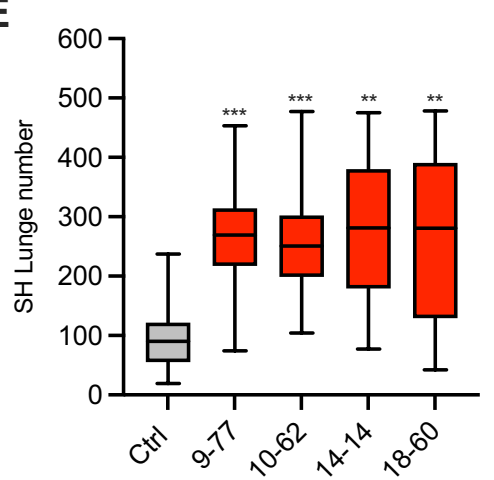

$\mathbf{F}$

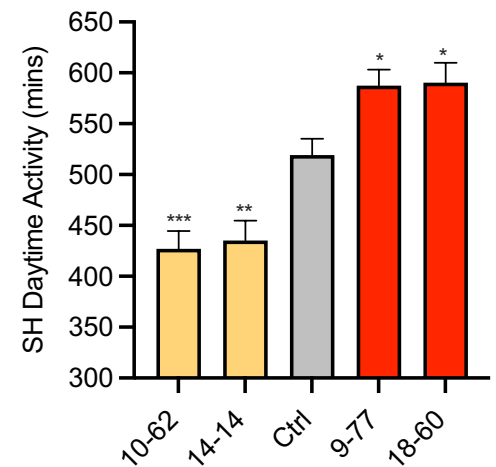

G

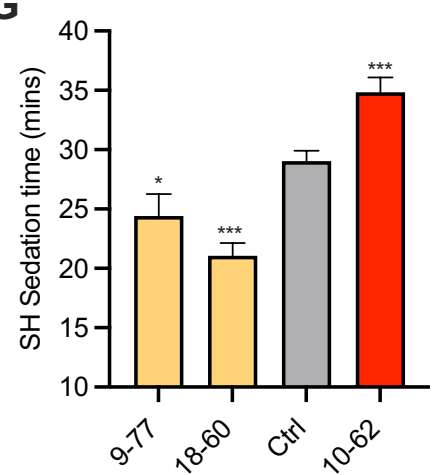

Figure 1. A forward genetic screen for social isolation mutants. (A-C) Social isolation increases aggression, daytime locomotor activity and ethanol sedation resistance in male flies $\left({ }^{* * *} \mathrm{p}<0.0001\right.$, Mann-Whitney $\mathrm{U}$ test). (A) Aggression was measured as the number of lunges in $20 \mathrm{~min}(\mathrm{n}=24)$; (B) Total daytime activity (min) was measured in the DAM assay $(n=29)$; (C) Ethanol resistance was measured as median sedation time ( $\mathrm{min})$ $(\mathrm{n}=18)$. (D) A histogram of the aggression screen of 1606 P-element lines showing frequency of lines with mean lunges. Mean and median lunge number was approx. 85 lunges $(\mathrm{SD} \pm 65)$. Mutants with a lunge mean $<28$ ( 1 SD below mean, blue) were considered hypo-aggressive and lunge mean $>180$ (1.5 SD above mean, red) hyperaggressive. (E) SH lunge number of activity and aggression mutants ${ }^{* * *} \mathrm{p}<0.0005,{ }^{* *} \mathrm{p}<0.0066$, KruskalWallis Test with Dunn's MCT, $\mathrm{n}=15-24$ ). (F) SH activity of activity and aggression mutants (hyperaggressive and hypoactive (yellow), hyperaggressive and hyperactive (red) $\left({ }^{*} \mathrm{p}<0.0279,{ }^{* *} \mathrm{p}<0.0048,{ }^{* * *} \mathrm{p}<0.0003\right.$,

One-Way ANOVA with Dunnett's MCT, $\mathrm{n}=30-46$ ). (G) SH ethanol sedation times of 3 activity and aggression mutants $\left({ }^{*} \mathrm{p}<0.0481,{ }^{* *} \mathrm{p}<0.0009\right.$, One-Way ANOVA with Dunnett’s MCT, $\left.\mathrm{n}=6-26\right)$.

\section{Results}

A forward genetic screen for social isolation mutants. Male flies socially isolated for five days show obvious, robust, and quantifiable increases in aggression, daytime locomotion, and resistance to ethanol sedation (Fig. 1A-C) ${ }^{23,25-27}$. These changes in behavior suggest that isolation induces an internal state change that modifies multiple behaviors ${ }^{35}$. To identify genes that may regulate this state, I sought to identify mutants with abnormal levels of isolation-induced aggression, activity and ethanol resistance. The strategy (Supplementary Fig. S1) was to first screen for aggression-related mutants, then screen aggression mutants for abnormal locomotor activity. Aggression and activity mutants were then tested for ethanol resistance. Any gene affected in a mutant which had abnormal levels of all three behaviors when single-housed (SH), but not group-housed (GH), was therefore likely central to regulating isolation-induced behavior.

To identify aggression mutants, I screened the Heberlein collection of 1606 lines that each have a single random insertion of a P-GAL4 element that affects the level of gene transcription. Male flies were isolated for five days, and aggression measured (Fig. 1D). Aggression was quantified as the total number of lunges performed between two males of the same genotype in $20 \mathrm{~min}$ (see Methods). I defined a normal level of aggression based on the mean and median of the whole population ( $\sim 85$ lunges $/ 20 \mathrm{~min})$. To identify aggression mutants at the ends of the distribution, lines were considered hyperaggressive if their lunge mean was greater than $1.5 \mathrm{SD}$ above the mean (180 lunges/20 $\mathrm{min}$ ) and due to the left skew in the distribution, hypo-aggressive if their lunge mean was less than $1 \mathrm{SD}$ below the mean (28 lunges/20 $\mathrm{min}$ ).

In total, $15 \%$ of the population (244 lines) met these criteria and were backcrossed to the genetic background $(w$ Berlin) for five generations to remove unlinked modifiers. After retesting, 183 lines $(75 \%)$ lost their aggressive phenotype and 61 lines remained mutant (15 hypo-aggressive and 46 hyperaggressive), demonstrating a significant influence of unlinked modifiers on SH aggression. Using inverse PCR, the P-element insertion site in all aggressive mutants was mapped (Supplementary Table S1). Importantly, insertion sites included several gene loci previously associated with aggression (e.g. lama, RtnL1 and $\mathrm{kis}^{36-38}$ ), validating the screen. To be sure being isolated was the primary cause of increased aggression, hyperaggressive lines were also tested for aggression 
A

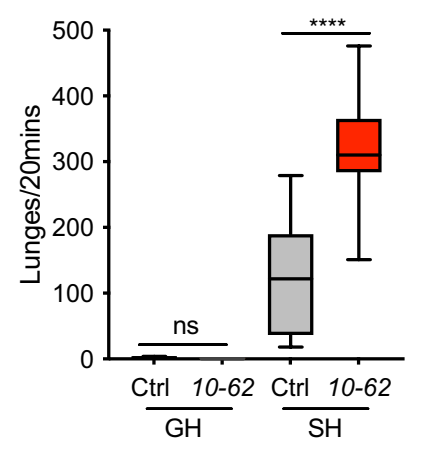

B

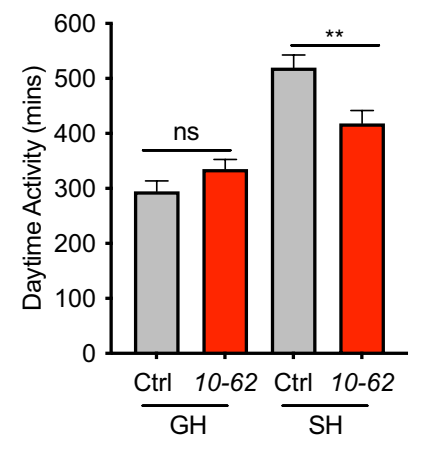

C

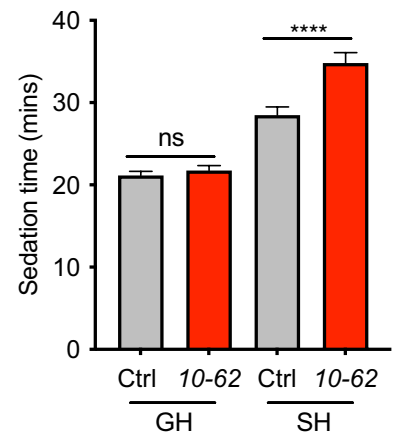

D

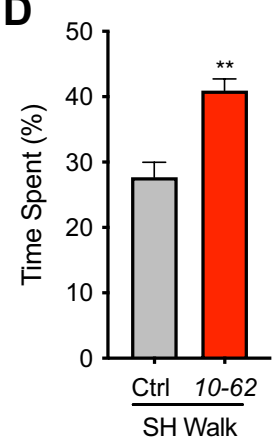

E

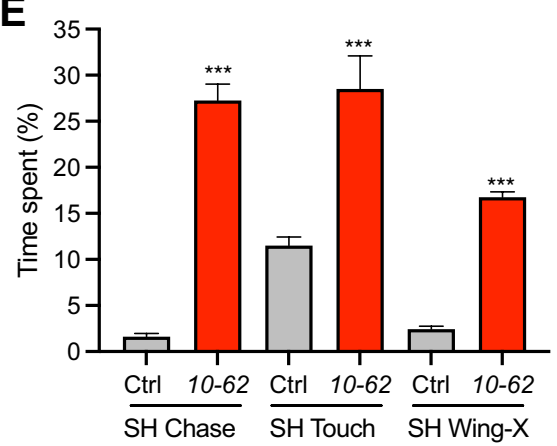

$\mathbf{F}$

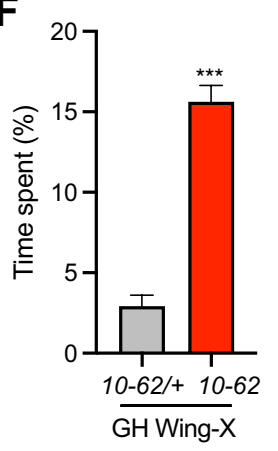

Figure 2. 10-62 has an excessive level of social behaviors. (A) GH 10-62 males were as unaggressive as GH control $(\mathrm{p}=0.991)$, but hyperaggressive when $\mathrm{SH}\left({ }^{* * *} \mathrm{p}<0.0001 ; 2\right.$-Way ANOVA with Sidak’s MCT, $\left.\mathrm{n}=12-24\right)$. (B) 10-62 males had normal locomotor activity when GH $(\mathrm{p}=0.2892)$, but decreased activity when SH ( ${ }^{* *} \mathrm{p}<0.0019 ; 2$-Way ANOVA with Sidak's MCT, $\left.\mathrm{n}=29-32\right)$. (C) GH 10-62 males had normal resistance to ethanol sedation $(\mathrm{p}=0.8609)$, but increased ethanol resistance when $\mathrm{SH}\left({ }^{* * * *} \mathrm{p}<0.0001 ; 2\right.$-Way ANOVA with Sidak's MCT, $\mathrm{n}=13-18$ ). In the fly bowl, SH 10-62 males showed increased time spent (as \%) (D) walking $\left({ }^{* *} \mathrm{p}<0.0019, \mathrm{n}=8\right.$, Mann-Whitney Test) and (E) chasing, touching, and performing single wing-extensions (Wing-X) $\left({ }^{* *} \mathrm{p}<0.0002\right) ; \mathrm{n}=8$, Mann-Whitney Test). (F) GH 10-62 males also showed increased male-male courtship behavior in the fly bowl $\left.{ }^{* * *} \mathrm{p}<0.0002\right) ; \mathrm{n}=8$, Mann-Whitney Test).

when GH. Here, 4/46 hyperaggressive lines were also aggressive when GH and not considered further (Supplementary Table S1).

Next, using the Drosophila Activity Monitor (DAM), I measured the daytime locomotor activity of SH aggression mutants when GH and SH (Supplementary Table S2). The majority (37/61) had normal activity in both housing conditions and not considered further. Another fourteen lines had abnormal activity when $\mathrm{GH}$ and were also ruled out. In summary, after testing SH mutants in both aggression and activity assays four SH hyperaggressive mutants also had abnormal activity when SH, but not GH (Fig. 1E, F, Supplementary Table S3). Two hyperaggressive mutants were also hyperactive when $\mathrm{SH}$, suggesting these lines (9-77 and 18-60) were more sensitive to isolation. Curiously, the other two hyperaggressive mutants were hypoactive when SH (10-62 and 14-14), suggesting a more complex relationship between candidate gene and isolation-induced aggression and activity.

Next, I tested $3 \mathrm{SH}$ aggression and activity mutants for abnormal resistance to ethanol sedation (Supplementary Table S4). While all had normal GH ethanol resistance, only SH 10-62 was more ethanol resistant than SH control (Fig. 1G). While there was no correlation in the direction of aggression and ethanol resistance, there was an inverse correlation between activity level and ethanol resistance.

In summary, this screen identified three mutants that had abnormal levels of aggression, locomotor activity and ethanol resistance when isolated. Therefore, the genes affected in these mutants are likely central in regulating the effects of isolation. However, no mutant affected all three isolation-induced behaviors in the same direction, suggesting the relationship between each gene and these behaviors is complex. I choose to examine line 10-62 in more detail, as its phenotype was the most robust and its P-element is inserted in hts (aka adducin), an actin regulator that is known to regulate synaptic stability across species ${ }^{39,40}$. Of note, synapse stability is also affected by social isolation $^{31}$, actin dynamics regulates isolation-induced social dominance behavior in mice ${ }^{41}$, and is strongly implicated in mental health disorders in humans ${ }^{42}$.

10-62 has an excessive level of social behaviors. While GH 10-62 males had normal levels of aggression, locomotor activity and ethanol resistance, $\mathrm{SH}$ 10-62 males were hyperaggressive, less active, and more resistant to ethanol sedation compared to the SH control (Fig. 2A-C). 10-62 fecundity appeared normal, and males had no obvious morphological defects in brain structure (Supplementary Fig. S2). One notable difference 
A

\begin{tabular}{|l|l|}
\hline HTS isoform & \multicolumn{1}{c|}{ Transcripts } \\
\hline htsM/Add1 & hts- $R I / L / M / S / O$ \\
\hline Add2 & $h t s-R Q / R$ \\
\hline ShAdd & $h t s-R C / H / J$ \\
\hline hts-PD & hts- $R D$ \\
\hline hts-PP & hts- $R P$ \\
\hline
\end{tabular}

B

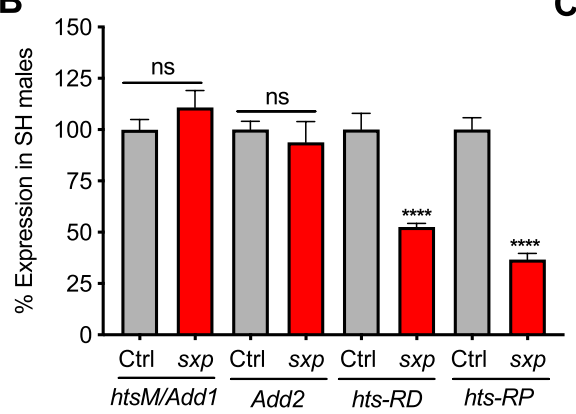

C

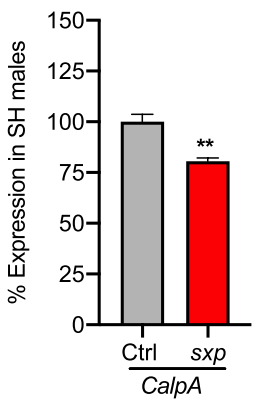

Figure 3. $\operatorname{sxp}$ Flies have Reduced Expression of Specific hts Isoforms and CalpA. (A) The HTS protein isoforms expressed in males and encoding transcripts. (B) By q-PCR, no difference in expression level of $h t s M / A d d 1$ or $A d d 2$ transcripts in $\mathrm{SH} \operatorname{sxp}(\mathrm{p}>0.05, \mathrm{n}=6)$ was detected, but there was a significant reduction in $h t s-R D$ and $h$ ts $-R P\left({ }^{\star * * *} \mathrm{p}<0.0001 ; \mathrm{n}=6\right.$, Unpaired t-test). (C) SH $\operatorname{sxp}$ also had a mild reduction in CalpA expression $\left({ }^{* *} \mathrm{p}<0.0086 ; \mathrm{n}=3\right.$, Unpaired t-test).

was that $10-62$ body mass was $~ 5 \%$ heavier in both GH and SH conditions (Supplementary Fig. S2). Given its elevated SH aggression and SH ethanol resistance, it seemed counterintuitive that SH 10-62 males had decreased daytime locomotor activity (Fig. 2B). A potential reason for this unexpected finding is that the DAM assay is a single fly assay, while both the aggression and ethanol resistance assays are not. Therefore, I measured the locomotor activity of SH 10-62 in the fly bowl, a relatively large arena ${ }^{43}$ where groups of twenty SH males interact. Interestingly, using the Janelia Automatic Animal Behaviour Annotator ${ }^{44}$ to quantify behavior I measured a significant increase in the time SH 10-62 spent walking (Fig. 2D). More strikingly, I also observed an increased time spent chasing and touching, as well as performing single-wing extensions, that are usually reserved for male-female courtship (Fig. 2E, Supplementary Movies S1, S2). Of note, the increased male-male courtship of SH 10-62 was also observed in GH 10-62 males (Fig. 2F, Supplementary Fig. S2), suggesting the excessive male-male courtship of 10-62 was independent of isolation. Indeed, SH did not significantly increase male-male courtship in control flies (Supplementary Fig. S2). Therefore, in the aggression chamber, which is relatively small and contains food, SH 10-62 males were more aggressive than normal, while in the fly bowl chamber, which is relatively large and has an absence of food, they were more sexual than normal. Sex or genotype preference was not tested, though in the fly bowl, 10-62 males also spent more time wing-flicking (Supplementary Fig. S2), a defensive behavior possibly initiated in response to other males' courtship advances.

In summary, when alone in the DAM assay SH 10-62 males had decreased activity, but when grouped with other SH 10-62 males in the fly bowl they had increased activity. This increased activity was likely driven by its excessive male-male courtship, which was independent of housing regime. Since the behavioral repertoire of 10-62 males included excessive levels of sex, aggression, and ethanol resistance, I named the mutant sex pistol $(\operatorname{sxp})$ in reference to the anarchistic 70's punk band.

Sex pistol has reduced expression of hts and CalpA. The P-element in sxp is inserted between the 1st and 2nd exons of hts (or adducin), a gene which encodes a conserved protein that forms heterodimers or tetramers and is known to regulate actin dynamics and synaptic stability across species ${ }^{39,40,45}$. Drosophila hts encodes multiple protein isoforms. Males have five, called Add1/HtsM, Add2, ShAdd, hts- $\mathrm{PD}^{46}$ and hts-PP (flybase.org) which mainly differ in the C-terminal domain (Fig. 3A). To decipher if there was any change in level of $h t s$ transcripts in sxp, I performed q-PCR with various $h t s$ primers on RNA extracted from isolated male heads. Comparing SH control and SH sxp males, I did not observe a difference in expression of Add1/HtsM, the predominant isoform expressed in the brain ${ }^{39}$, or $A d d 2$ (Fig. 3B). However, sxp did have an approximately $50 \%$ reduction in $h t s-R D$ and a $38 \%$ reduction in $h t s-R P$ transcripts. Of note, expression of $h t s-R D / R P$ in control and sxp flies was lower than levels of $A d d 1$ (with an average Ct value of $\sim 29$ vs 25), suggesting a reduced or more localized expression. Due to sequence similarity, I could not assess if ShAdd was affected. I did not detect a difference in any $h t s$ transcript tested between $\mathrm{GH}$ and $\mathrm{SH}$ flies, suggesting isolation does not alter $h t s$ expression in sxp or control flies (Supplementary Fig. S3).

As the P-element also sits close ( $\sim 700 \mathrm{bp})$ to $\mathrm{CalpA}$, a calcium-dependent endopeptidase that regulates dendritic pruning ${ }^{47}$, I next checked levels of CalpA (with primers common to all four isoforms). Interestingly, $\mathrm{SH}$ sxp males had a small (approximately 20\%) but significant, reduction of CalpA expression (Fig. 3C). As with hts, CalpA expression was unaffected by isolation (Supplementary Fig. S3). In summary, the P-element insertion in sxp significantly reduced expression of $h t s-R D, h t s-R P$ and CalpA, but neither $h t s$ nor CalpA transcription was altered by isolation. As this analysis was performed on whole male heads, I cannot draw conclusions about gene expression level in sub-populations of cells in the brain or body.

$h t s-R D / R P$ limits isolation-induced aggression. I first tested whether the reduced $h t s-R D / R P$ in $s x p$ males was the cause of their hyperaggressive phenotype. This seemed likely as several $h t s$ transposons, including a P-Bac insertion $15 \mathrm{~Kb} 5$ ' of CalpA, were also hyperaggressive (Supplementary Fig. S4). To do this, I attempted to rescue $\operatorname{sxp}$ with a $h t s$ genomic construct $(g-h t s)$ that spans the entire $h t s$ locus and its regulatory sequences, but 


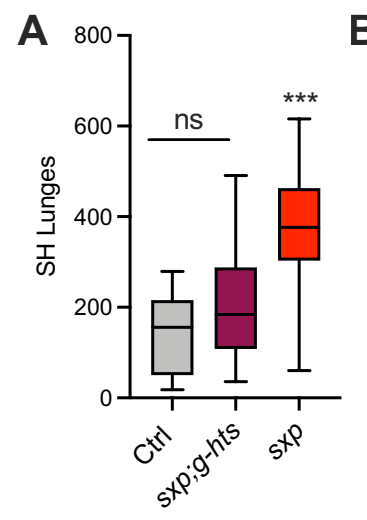

B

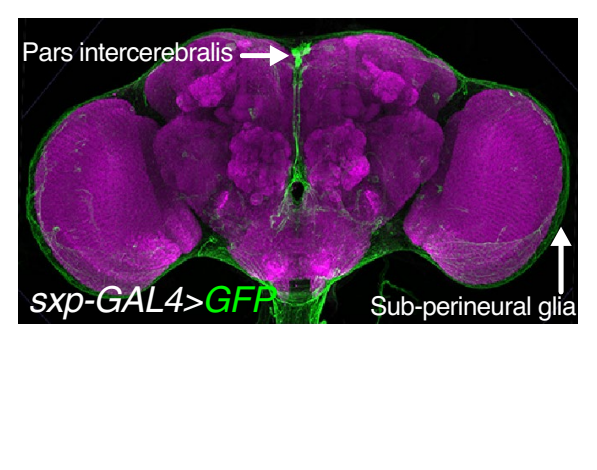

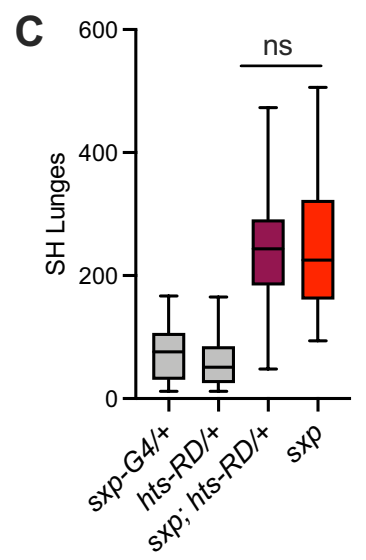

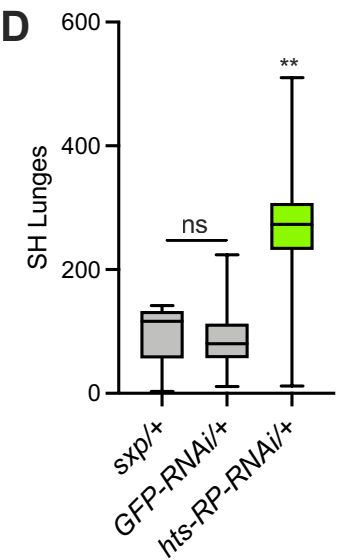

Figure 4. hts limits isolation-induced aggression. (A) Inclusion of genomic hts construct (fTRG-585) restored normal levels of aggression to $\operatorname{sxp}(\mathrm{p}>0.05, \mathrm{n}=21-24$, Kruskal-Wallis Test with Dunn's MCT). (B) Expression of sxp-GAL4/+ in adult male head visualized with GFP, predominately staining PI neurons and sub-perineural glia. (C) Expression of $h t s-R D$ with $\operatorname{sxp}-G A L 4$ did not rescue $\operatorname{sxp}{ }^{* * * *} \mathrm{p}<0.0001, \mathrm{n}=20-24$, Kruskal-Wallis Test with Dunn's MCT). (D) Compared to $\operatorname{sxp}-G A L 4 /+$ and UAS-GFP-RNAi/+ , UAS-hts-RP-RNAi/+ was hyperaggressive $\left({ }^{* *} \mathrm{p}=0.0095, \mathrm{n}=12-25\right.$, Kruskal-Wallis Test with Dunn's MCT).

not the complete coding sequence of $\operatorname{Calp} A^{48}$. Indeed, inclusion of the hts-genomic construct in the $\operatorname{sxp}$ mutant, restored normal levels of aggression (Fig. 4A). Therefore, given the nature of the hts lesion in $s x p$, I conclude that $h t s-R D$ and/or $h t s-R P$ limit the level of isolation-induced aggression, and that reduced CalpA is not the cause of its excessive $\mathrm{SH}$ aggression.

To try and decipher where $h t s-R D$ or $h t s-R P$ regulate aggression I first used $\operatorname{sxp}-G A L 4$, which is expressed in pars-intercerebralis (PI) neurons and sub-perineural glia (Fig. $4 \mathrm{~B}$ ), and may represent the $h t s-R D / R P$ expression pattern. However, driving UAS- $h t s-R D^{46}$ with $s x p-G A L 4$, did not normalize $s x p$ aggression (Fig. $4 \mathrm{C}$ ). Therefore, if $h t s-R D$ is involved, either its expression in these cells was insufficient, or possibly the expression level required for rescue was not optimal. Attempts to rescue by broadening the $\operatorname{sxp}-G A L 4$ expression pattern with either a pan-neuronal or a pan-glia GAL4 driver failed, as all resulted in hyperaggressive GAL4/+ control flies, making significant difference between genotypes hard to detect (Supplementary Fig. S4). Similarly, technical limitations also prevented me from testing a role for $h t s-R P$, as the available $U A S$ - $h t s-R P$ - $R N A i$ line was hyperaggressive as a heterozygote (Fig. 4D). In summary, although hyperaggressive control phenotypes precluded me from dissociating the roles of $h t s-R D$ and $h t s-R P$ and identifying where they function, my results show that at least one of these $h t s$ transcripts acts to limit aggression when male flies are isolated.

Decreasing CalpA in sxp-GAL4 cells increases male-male courtship. Using the hts genomic construct $(g-h t s)$, I next attempted to normalize the excessive male-male courtship of GH sxp in the fly bowl. Curiously, unlike aggression, the $h t s$ genomic construct failed to rescue time spent chasing, touching, and performing single-wing extensions (Fig. $5 \mathrm{~A}$ ). Therefore, I conclude that $h t s-R D / R P$ does not limit male-male courtship. Given this, I next tested if CalpA might regulate male-male courtship by using RNAi to downregulate CalpA in $\operatorname{sxp}$-GAL4 expressing cells. Interestingly, driving a UAS-CalpA-RNA $i$ with $s x p$-GAL4 significantly increased chasing, touching and single-wing extensions in GH males (Fig. 5B, Supplementary Fig. S5). Importantly, as a control for a non-specific RNAi effect, driving an UAS-hts-RNAi line that reduces all hts isoforms with $\operatorname{sxp}$-GAL4 did not increase single-wing extensions in the fly bowl (Supplementary Fig. S5). These results suggest that CalpA functions in $\operatorname{sxp}$-GAL4 cells to inhibit male-male courtship. Therefore, because the genomic hts construct failed to normalize male-male courtship, reduced CalpA appears, at least in part, to be responsible for the excessive male-male courtship in GH sxp males.

dILP5 is overexpressed in sxp and increases male-male courtship. The insulin-producing neurons in the PI (PI-IPCs) co-express DILP2, DILP3 and DILP5 and have been shown to regulate aggression, locomotor activity and ethanol resistance (reviewed $\mathrm{in}^{49}$ ). Closer examination of $\operatorname{sxp}$-GAL4 expression in the PI, revealed that one sxp-GAL4 neuron was an IPC (Fig. 5C), while the rest (about 14 cells) were intermingled, but exclusive from them. As cells juxtaposed to the PI-IPCs have been implicated in non-autonomously regulating insulin release $^{50-52}$, I next examined levels of brain derived $d I L P 2$, dILP3 and $d I L P 5$ in $s x p$ heads by q-PCR. Interestingly, while $d I L P 2$ and $d I L P 3$ expression were unaffected in GH $\operatorname{sxp}$ (Supplementary Fig. S5), dILP5 was highly overexpressed in the heads of both GH and SH sxp males (Fig. 5D), suggesting an aspect of energy homeostasis is altered in $\operatorname{sxp}$ males. Curiously, these q-PCR experiments also revealed that social isolation decreases dILP5 expression, in controls by approximately $50 \%$. This isolation-induced reduction of $d I L P 5$, is similar to the isolation-induced reduction of drosulfakinin $(d s k)^{53}$ another neuropeptide also expressed in the PI-IPCs ${ }^{54}$ which regulates aggression ${ }^{53,55}$. However, $d s k$ levels in the heads of $\mathrm{GH}$ and $\mathrm{SH} \operatorname{sxp}$ males were normal (Supplementary Fig. S5), suggesting $d s k$ down regulation by social isolation is normal in $\operatorname{sxp}$ and not the cause of its excessive $\mathrm{SH}$ aggression. 
A

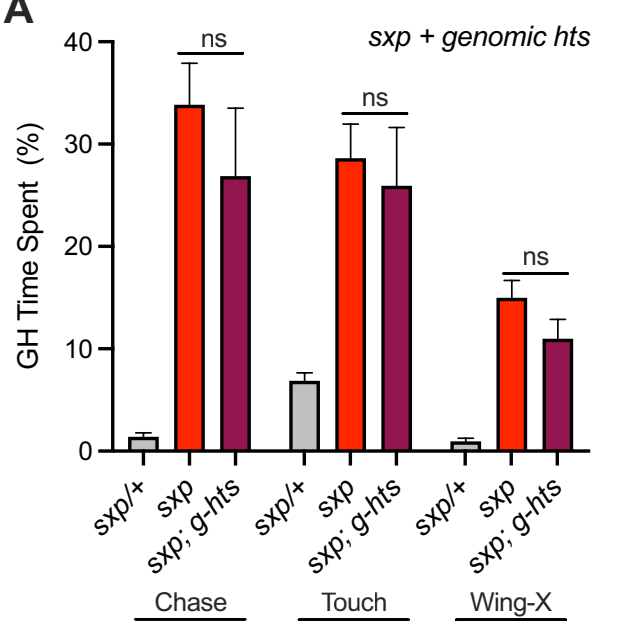

B

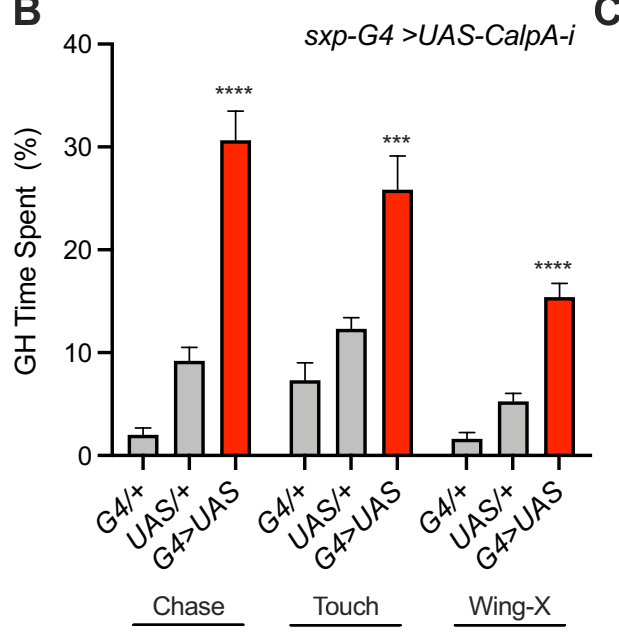

C
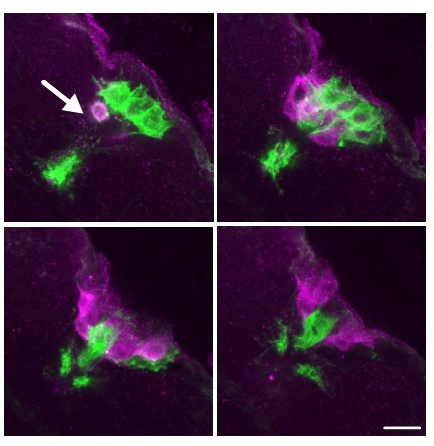

$\operatorname{sxp-G4>GFP}$

$+d I L P 5 A b$
D

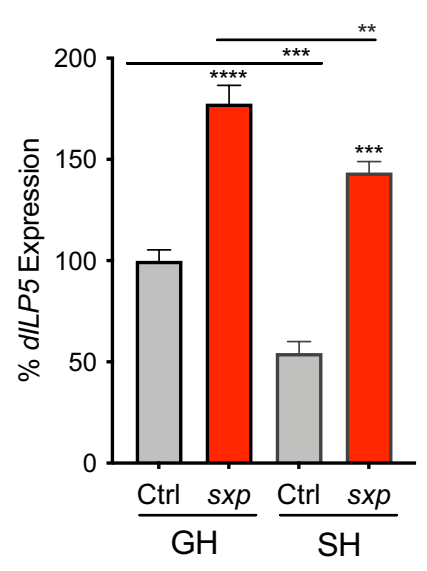

E



F

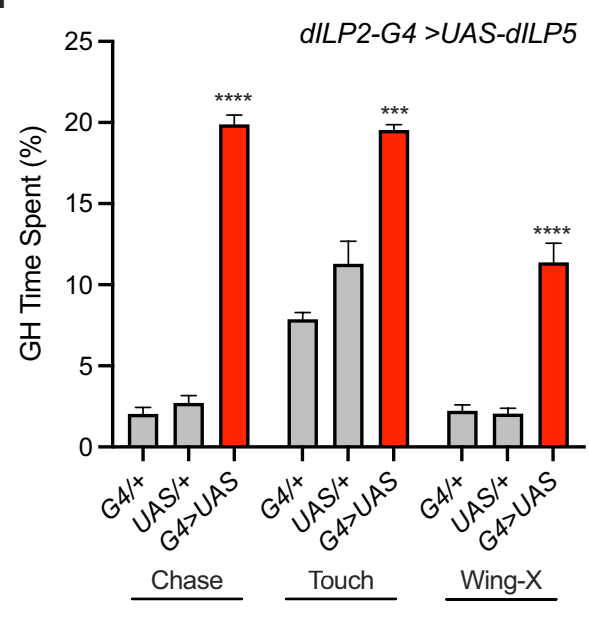

Figure 5. CalpA and $d I L P 5$ regulate male-male courtship. (A) Expressing hts genomic construct $(g$ - $h t s)$ did not restore normal levels of male-male chasing, touching and single-wing extensions of GH sxp in the fly bowl ( $\mathrm{p}>0.05, \mathrm{n}=4$, One-Way ANOVA, with Tukey's MCT) (B) Driving UAS-CalpA-RNAi with $s x p-G A L 4$ increased chase, touch and single-wing extensions in GH flies $\left({ }^{* * *} \mathrm{p}<0.0001,{ }^{* *} \mathrm{p}<0.0002, \mathrm{n}=3-6\right.$, OneWay ANOVA, with Tukey's MCT). (C) Sub-stacks of a Z-projection showing expression of sxp-GAL4 neurons visualized with GFP (green) in the PI. Except for one neuron (arrow), GFP expression is intermingled with, but excluded from, DILP5 expressing cells visualized with DILP5 Ab (purple). Scale bar $=10 \mu \mathrm{m}$. (D) By q-PCR, dILP5 is overexpressed in GH and SH male $\operatorname{sxp}$ heads $\left({ }^{* * *} \mathrm{p}<0.0001, \mathrm{n}=6\right)$. dILP5 is also reduced by social isolation in both controls and $\operatorname{sxp}\left({ }^{* * *} \mathrm{p}<0.0002,{ }^{* *} \mathrm{p}<0.0085, \mathrm{n}=4-6\right.$, Two-way ANOVA with Sidak's MCT). (E) Overexpression or reduction of dILP5 by driving UAS-dILP5 or UAS-dILP5-RNAi with dILP2-GAL4 did not increase SH aggression ( $\mathrm{p}>0.05, \mathrm{n}=21-24$, Kruskal-Wallis Test with Dunn's MCT). (F) Overexpression of dILP5 with dILP2-GAL4 did increase male-male chasing, touching and single-wing extensions of GH flies in the fly bowl ( ${ }^{* * *} \mathrm{p}<0.0001,{ }^{* *} \mathrm{P}<0.0051, \mathrm{n}=4-8$, One-way ANOVA with Tukey's MCT).

Given the high level of dILP5 in the heads of $\operatorname{sxp}$ males, I next tested if overexpressing dILP5 in the PI-IPCs phenocopied any of its excessive social behaviors. Overexpression of $d I L P 5$ with $d I L P 2-G A L 4$ did not increase SH aggression (Fig. 5E). Therefore, it seems likely that $d I L P 5$ overexpression in $s x p$ does not increase aggression. This is supported by the lack of aggression in GH sxp flies (Fig. 2A), where dILP5 is also overexpressed (Fig. 5D). However, in the fly bowl, dILP5 overexpression with $d I L P 2-G A L 4$ did increase male-male chasing, touching and single-wing extensions of GH flies (Fig. 5F). Therefore, while dILP5 overexpression does not appear to promote the excessive aggression of SH $\operatorname{sxp}$, it likely contributes to increased male-male courtship.

Finally, as isolation increases aggression as well as reduce $d I L P 5$ expression by $50 \%$ in control flies (Fig. 5D), I also tested if knockdown of dILP5 in PI-IPCs affected SH aggression. However, further reducing dILP5 by driving UAS-dilp5-RNAi with dILP2-GAL4 in SH flies did not affect aggression (Fig. 5E). Therefore, in control males, it seems unlikely that isolation-induced reduction of dILP5 increases SH aggression. Furthermore, the isolation-induced reduction of $d I L P 5$ is also unlikely to increase male-male courtship, as this behavior was not strongly induced by isolation (Supplementary Fig. S2). 
Taken together, these results suggest reduced $h t s-R D / R P$ in $\operatorname{sxp}$ males is the cause of its excessive $\mathrm{SH}$ aggression, while increased $d I L P 5$, and possibly reduced CalpA, is the cause of its excessive male-male courtship. Therefore, I conclude that $h t s-R D / R P$ functions to limit the level of isolation-induced aggression, while $\operatorname{Calp} A$ inhibits and chronically high $d I L P 5$ increases, male-male courtship.

\section{Discussion}

In this study, I sought to identify genes central to regulating the magnitude of behaviors induced by social isolation. In total, three mutants and candidate genes were identified that affected isolation-induced aggression, locomotor activity and ethanol resistance. However, in none of these mutants was the direction of behavioral regulation consistent across all behaviors (some behaviors were increased, while others decreased), revealing a genetic idiosyncrasy that did not fit a simple model of a single gene acting unidirectionally, in parallel and in different brain regions ${ }^{34}$.

The $\operatorname{sxp}$ mutant male had decreased activity when isolated and alone, and excessive aggression and ethanol resistance when re-socialized. Regardless of housing regime and in the absence of food and/or more space, sxp also had increased male-male courtship. The cause of its unusual behaviors was a P-element insertion that disrupts expression of two neighboring genes, $h t s$ and CalpA, as well as an indirect effect on dILP5 expression. Specifically, hts-RD/RP and CalpA were reduced while $d I L P 5$ (on a different chromosome) was increased. Experiments suggest $h t s-R D / R P$ limits the level of isolation-induced aggression in as yet undefined cells, while CalpA functions in $s x p-G A L 4$ cells and $d I L P 5$ in the PI-IPCs to regulate male-male courtship. It was not specifically tested which gene disruption(s) regulate isolation-induced hyperactivity or ethanol resistance, or if $\operatorname{sxp}$ females also show abnormal responses to being isolated.

$\mathrm{Hts} / \mathrm{adducin}$ is a highly expressed protein in the $\operatorname{brain}^{56}$, consisting of $\alpha / \beta$ - or $\alpha / \gamma$ heterodimers or tetramers that function to bundle actin filaments, cap their growing end, and bind spectrin. In doing so, adducin regulates cytoskeletal dynamics and distribution of plasma membrane proteins. Vertebrates have three adducin genes ( $\alpha$-adducin/Add1, $\beta$-adducin/Add2, and $\gamma$-adducin/Add3) (reviewed in ${ }^{57}$ ), while Drosophila has one ( $h t s$ ). Adducin is best known in the nervous system for stabilizing synapses ${ }^{39,40}$, but they also regulate axon guidance ${ }^{46}$ and diameter ${ }^{58}$. Most studies implicate the 'business end' of adducin to be its C-terminal MARCKS domain (related to myristoylated alanine-rich $\mathrm{C}$ kinase substrate protein) ${ }^{59}$, which is lacking in both $h t s-R D$ and $h t s-R P$. However, $h t s-R D$ can rescue axon guidance defects in $h t s$ nulls, suggesting the MARCKS domain is not essential for spectrin binding and possibly other actin related functions ${ }^{46}$. Nothing is known about $h t s-R P$, which has a large and unique C-terminal domain. As isolation does not affect $h t s-R D / R P$ transcription (Supplementary Fig. S3) and because GH $\operatorname{sxp}$ males are not aggressive, hts- $R D / R P$ may also be regulated post-translationally. Indeed, in mice, an enriched environment increases $\beta$-adducin phosphorylation ${ }^{60}$.

My attempts to determine in which cells $h t s-R D / R P$ functions to limit aggression failed, in part because control lines were hyperaggressive. Of note, these hyperaggressive control lines also displayed excessive male-male courtship in the fly bowl, suggesting the presence of food and/or the difference in space between the aggression chamber and fly bowl may have a significant effect on behavior ${ }^{61,62}$. It will be interesting to see if hyperaggressive flies in general show excessive male-male courtship in the absence of food and females. The reason for the hyper-aggression in these control lines is not clear, but as many genes regulate aggression ${ }^{36}$, it could be due to the sum of insertional effects in these randomly inserted P-GAL4 elements. Alternatively, as not all stocks were backcrossed at the same time, it may also be due to an accumulation of modifiers in parental stocks. Of note $75 \%$ of aggression mutants from the original screen were normalized after backcrossing for five generations, suggesting significant effects of time. As $h t s-R D / R P$ expressing cells were not located, the effect of $h t s-R D / R P$ reduction on cell morphology and/or neuronal circuitry is yet to be ascertained, though its likely they regulate an aspect of actin remodeling. This could be a developmental effect that is only uncovered when $\operatorname{sxp}$ is isolated, or an acute failure to alter actin dynamics in response to the change in social environment. Given these findings in the fly, it is noteworthy that in humans, adducin has been associated with bipolar disorder ${ }^{63}$, schizophrenia ${ }^{64}$ and alcohol-use disorders ${ }^{65}$, conditions where emotions can be overpowering.

Calpains are a family of calcium-dependent cysteine proteases with numerous substrates, including adducin ${ }^{66}$, $\alpha$-spectrin ${ }^{67}$ and the glutamate receptor GluRIIA ${ }^{68}$. In Drosophila CalpA regulates immune function ${ }^{69}$ and dendritic pruning ${ }^{47}$, a developmental process also requiring actin remodeling. While the reduction of CalpA is relatively small in $\operatorname{sxp}$ males, it does seem to play a role in inhibiting male-male courtship as the genomic $h t s$ construct failed to normalize it in $\operatorname{sxp}$, while reduction of CalpA with $\operatorname{sxp}$-GAL4 phenocopied it. Interestingly, inhibitors of calpain increase insulin secretion ${ }^{70}$. Therefore, CalpA may inhibit dILP5 expression by decreasing its secretion. Because only one sxp-GAL4 neuron expressed dILP5 (Fig. 5C), it seems unlikely that a $20 \%$ CalpA reduction in one cell is increasing dILP5 expression by $\sim 50 \%$. Rather, CalpA may function in other $\operatorname{sxp}$ GAL4/dILP5-negative cells that regulate insulin secretion, such as the juxtaposed fat-sensing PI neurons ${ }^{50}$, the taotie neurons ${ }^{52}$ or even the sub-perineural glia ${ }^{71}$.

Although it was not established which gene disruption(s) in sxp results in dILP5 overexpression, the data suggests $d I L P 5$ does not regulate isolation-induced aggression but, when chronically overexpressed, does promote male-male courtship. As SH sxp males are hypoactive and $d I L P 5$ nulls are hyperactive ${ }^{72}, d I L P 5$ may also regulate isolation-induced hyperactivity. Since $d I L P 5$ is also reduced during starvation ${ }^{73}$, the reduction of $d I L P 5$ when isolated suggests isolated flies are in some way food deprived. Indeed, although SH flies have a normal appetite ${ }^{74}$, they do weigh less than GH flies (Supplementary Fig. S2). Interestingly, socially isolated ants retain food in their crop (a temporary food storage chamber), preventing its use as an energy source ${ }^{75}$. This mechanism of food retention may therefore explain why $\mathrm{SH}$ flies have normal appetite, yet reduced weight and dILP5 expression. Intriguingly in humans, food and social deprivation activate the same mid-brain region ${ }^{76}$. 
In summary, this study identified several candidate genes that regulate sensitivity to being socially isolated. The characterization of $\operatorname{sxp}$ revealed a molecular and behavioral complexity involving several genes not uncommon in psychiatric disorders ${ }^{77}$ and demonstrated the utility of Drosophila ${ }^{78,79}$ in untangling the complex relationships between genetics, the social environment and behavior.

\section{Materials and methods}

All flies were maintained on a 12 -h light-dark cycle on standard cornmeal-yeast-agar medium at $25^{\circ} \mathrm{C}$ and $60 \%$ humidity. All experiments were performed on 7-8-day old males.

Fly stocks. Fly strains were from the following labs/stock center and I appreciate their generosity. dILP2GAL4, PDF-GAL4, R5710-GAL4, Repo-GAL4 and Repo-GAL80 (Bloomington Stock Center); dILP3-GAL4 $4^{80}$; UAS-dILP5 (Ernst Hafen, Switzerland), UAS-hts-RD (Takashi Suzuki, Japan); UAS-hts-RNAi (GD29102), UAS-hts-RP-RNAi (KK113568), UAS-CalpA-RNAi (GD12275), UAS-dILP5-RNAi (GD16039) and fTRG-585 ${ }^{48}$ (genomic-hts, VDRC 318186) (VDRC); NP3613 (Kyoto Stock Center) and C00257 (Harvard). All stocks were backcrossed to $w$ Berlin for five generations to remove unlinked modifiers and normalize the genetic background.

Molecular characterization of hts allele. The location of the P-element insertion in $s x p$ was determined by inverse PCR. The P-element is located in the first hts intron at position 19424308, 515 bp downstream of exon 1. q-PCR was performed on 3-6 biological replicates; each replicate had 16-20, 6-day old male fly heads (three biological replicates/day, three triplicates $\mathrm{n}=1$ ). Tissue was homogenized in DNA/RNA shield (Zymo Research) and RNA was extracted using a Direct-zol kit (Zymo Research) and quantified and quality controlled with Nanodrop. 20 ng RNA per sample was used for DNA synthesis and q-PCR using RNA-to- $C_{T} 1$-Step Kit (Life Technologies). Taqman primers and designed by Applied Biosystems. q-PCR was performed and analyzed by comparative $\mathrm{C}_{\mathrm{T}}$ methods on a StepOne Plus Machine (Applied Biosystems). Expression levels were normalized and presented in terms of $\%$ expression $(100 \%=$ Relative value $=1)$.

Behavior assays. Most behavioral assays were performed on males on 2 independent days using 4-6 independent crosses with the same number of virgins for all crosses (to control for larval density and adult fly size). Single housing involved isolating 1-2 day old flies (non-virgins) in small glass vials for 6-7 days before testing. For group-housed controls 20 males in placed in a regular vial for the same period of time. To control for circadian effects on behavior, all assays were performed within $3 \mathrm{~h}$ of lights on. For GAL4/UAS experiments, experimental flies were compared with both the GAL4/+ and UAS/+ controls. Only experimental lines that differed from both controls in the same direction were considered to have a phenotype.

Aggression. Aggression assays were performed as previously described ${ }^{81}$. Aggression was measured by video recording two flies of the same genotype for $20 \mathrm{~min}$ in a $10 \mathrm{~mm}$ arena in a 12 -cell chamber at $25^{\circ} \mathrm{C}$. The bottom of the chamber was coated with a thin layer of $4 \%$ apple juice and agar medium, and walls of the chamber coated with Fluon (BioQuip, Rancho Dominguez, CA). Flies were habituated to the chamber for 5 min before recording. Movies were recorded at 30 frames/s using gVision (http://gvision-hhmi.sourceforge.net) video acquisition software run with Matlab (MathWorks, Natick, MA). Pairs of males were tracked and automated scores of lunging were derived using CADABRA software ${ }^{82}$. The screen controls for aggression were two independent $\mathrm{P}$ element lines that had a normal mean/median lunge number ( $\sim 100$ lunges/20 min $)$ compared to the population of 1600 strains that were initially screened (Heberlein line 10-195 or 5-116).

Locomotor activity. The locomotor/sleep activity was recorded using the Drosophila Activity Monitoring System (Trikinetics, Waltham, MA). Flies were placed in $65 \mathrm{~mm} \times 5 \mathrm{~mm}$ glass tubes and acclimated overnight before measurement of sleep/activity. Because all flies are isolated in the trikinetic tubes, the activity/sleep was measured for the first $24 \mathrm{~h}$ after acclimation. A sleep bout was defined as $5 \mathrm{~min}$ or more of immobility. Total daytime activity/sleep was extracted using S.C.A.M.P software from the Griffith lab. The control for activity was the same strain used for aggression (Line 5-116) or $w+$ Berlin, which were not significantly different.

Ethanol-induced sedation. Ethanol sedation assays were performed in the "booz-o-mat," an eight-chambered apparatus that delivers a specified concentration of ethanol vapor ${ }^{83}$. Sedation was assayed manually as described previously ${ }^{84}$ by exposing groups of twenty GH or SH males to an ethanol concentration of 100:50 (ethanol vapor:humidified air). Sedation time is the median time when $50 \%$ of flies are sedated. wBerlin was used as the control.

Fly bowl. A detailed account of Fly Bowl assay, data collection and analysis has been previously described ${ }^{85}$. Briefly, flies were gently loaded into the Fly Bowl by aspiration, each bowl had groups of 20 males. I simultaneously recorded 2-4 $20 \mathrm{~min}$ movies at $25^{\circ} \mathrm{C}$. As 2-4 bowls were loaded before the start of analysis, I took care to rotate genotypes to average out any difference in load time (that ranged from 32 to $482 \mathrm{~s}$ as GH flies were quicker to load than SH flies). Analysis was performed using the Janelia Automatic Animal Behavior Annotator (JAABA). I used five behavior classifiers previously described in ${ }^{85}$, using the JAABA interactive machine learning software $^{86}$. Each binary classifier corresponded to a different behavior. These classifiers are not mutually exclusive. A brief description of criteria used to train each behavior classifier is listed: Chase-one fly follows another moving fly and maintains a small, somewhat constant distance to the fly it is following. Touch-the fly makes contact with the body, wings, or legs of another fly, using its body or legs. Walk - the fly moves forward using 
approximately alternating movements of the mesothoracic legs. Wing extension-the fly unilaterally rotates a wing out from its body in the horizontal plane, often for extended periods of time. Wing-flick-the fly rapidly and symmetrically moves its wings horizontally out and back to their rest position, often multiple times in a row.

Immunocytochemistry. Immunocytochemistry was performed using standard techniques on 6-7-day old adult males. Briefly, heads were fixed in $2 \%$ PFA o/n at $4{ }^{\circ} \mathrm{C}$ before staining o/n in primary antibody. Antibodies used were Anti-GFP (Molecular Probes, A11122, 1:500), Mouse-anti-nc82 (Hybridoma Bank DSHB, 1:50), Anti-FAS-II (DSHB), Anti-Dilp5, 1:800 (courtesy of Prof. P. Leopold), Secondary antibodies were from Molecular Probes and used 1:500.

Statistics. Statistical analyses were performed using Prism Version 9 (GraphPad). When possible, statistical significance was established by first establishing if there was a normal distribution with a D'Agostino-Pearson normality test. Either a two-tailed t-test or a one-way or two-way analysis of variance (ANOVA), followed by the appropriate post-hoc tests (Unpaired t-test or Tukey's for normal distribution and a Mann-Whitney or KruskalWallis for non-Gaussian distributions. Alpha $=0.05$ ). Error bars represent min to max in aggression assays and SEM in all other graphs.

\section{Data availability}

Strains are available upon request. The author affirms that all data necessary for confirming the conclusions of the article are present within the article, figures, and tables.

Received: 31 January 2021; Accepted: 10 August 2021

Published online: 30 August 2021

\section{References}

1. Holt-Lunstad, J., Smith, T. B. \& Layton, J. B. Social relationships and mortality risk: A meta-analytic review. PLoS Med. 7, e1000316. https://doi.org/10.1371/journal.pmed.1000316 (2010).

2. Lim, M. H., Holt-Lunstad, J. \& Badcock, J. C. Loneliness: Contemporary insights into causes, correlates, and consequences. Soc. Psychiatry Psychiatr. Epidemiol. 55, 789-791. https://doi.org/10.1007/s00127-020-01891-z (2020).

3. Meyer-Lindenberg, A. \& Tost, H. Neural mechanisms of social risk for psychiatric disorders. Nat. Neurosci. 15, 663-668. https:// doi.org/10.1038/nn.3083 (2012).

4. Cacioppo, J. T. \& Cacioppo, S. Social relationships and health: The toxic effects of perceived social isolation. Soc. Personal Psychol. Compass 8, 58-72. https://doi.org/10.1111/spc3.12087 (2014).

5. Cacioppo, J. T., Hawkley, L. C., Norman, G. J. \& Berntson, G. G. Social isolation. Ann. N.Y. Acad. Sci. 1231, 17-22. https://doi.org/ 10.1111/j.1749-6632.2011.06028.x (2011).

6. Goossens, L. et al. The genetics of loneliness: Linking evolutionary theory to genome-wide genetics, epigenetics, and social science. Perspect. Psychol. Sci. 10, 213-226. https://doi.org/10.1177/1745691614564878 (2015).

7. Victor, C. R. \& Yang, K. The prevalence of loneliness among adults: A case study of the United Kingdom. J. Psychol. 146, 85-104. https://doi.org/10.1080/00223980.2011.613875 (2012).

8. Killgore, W. D. S., Cloonan, S. A., Taylor, E. C. \& Dailey, N. S. Loneliness: A signature mental health concern in the era of COVID19. Psychiatry Res. 290, 113117. https://doi.org/10.1016/j.psychres.2020.113117 (2020).

9. Day, F. R., Ong, K. K. \& Perry, J. R. B. Elucidating the genetic basis of social interaction and isolation. Nat. Commun. 9, 2457. https://doi.org/10.1038/s41467-018-04930-1 (2018).

10. Fone, K. C. \& Porkess, M. V. Behavioural and neurochemical effects of post-weaning social isolation in rodents-relevance to developmental neuropsychiatric disorders. Neurosci. Biobehav. Rev. 32, 1087-1102. https://doi.org/10.1016/j.neubiorev.2008.03. 003 (2008)

11. Walker, D. M., Cunningham, A. M., Gregory, J. K. \& Nestler, E. J. Long-term behavioral effects of post-weaning social isolation in males and females. Front. Behav. Neurosci. 13, 66-66. https://doi.org/10.3389/fnbeh.2019.00066 (2019).

12. Ehlers, C. L., Walker, B. M., Pian, J. P., Roth, J. L. \& Slawecki, C. J. Increased alcohol drinking in isolate-housed alcohol-preferring rats. Behav. Neurosci. 121, 111-119. https://doi.org/10.1037/0735-7044.121.1.111 (2007).

13. Whitaker, L. R., Degoulet, M. \& Morikawa, H. Social deprivation enhances VTA synaptic plasticity and drug-induced contextual learning. Neuron 77, 335-345. https://doi.org/10.1016/j.neuron.2012.11.022 (2013).

14. Stranahan, A. M., Khalil, D. \& Gould, E. Social isolation delays the positive effects of running on adult neurogenesis. Nat. Neurosci. 9, 526-533. https://doi.org/10.1038/nn1668 (2006).

15. Siuda, D. et al. Social isolation-induced epigenetic changes in midbrain of adult mice. J. Physiol. Pharmacol. 65, 247-255 (2014).

16. Cole, S. W. et al. Social regulation of gene expression in human leukocytes. Genome Biol. 8, R189. https://doi.org/10.1186/gb-20078-9-r189 (2007).

17. Tada, H. et al. Social isolation suppresses actin dynamics and synaptic plasticity through ADF/cofilin inactivation in the developing rat barrel cortex. Sci. Rep. 7, 8471. https://doi.org/10.1038/s41598-017-08849-3 (2017).

18. Matthews, G. A. et al. Dorsal raphe dopamine neurons represent the experience of social isolation. Cell 164, 617-631. https://doi. org/10.1016/j.cell.2015.12.040 (2016).

19. Cacioppo, J. T., Cacioppo, S., Capitanio, J. P. \& Cole, S. W. The neuroendocrinology of social isolation. Annu. Rev. Psychol. 66, 733-767. https://doi.org/10.1146/annurev-psych-010814-015240 (2015).

20. Wallace, D. L. et al. CREB regulation of nucleus accumbens excitability mediates social isolation-induced behavioral deficits. Nat. Neurosci. 12, 200-209. https://doi.org/10.1038/nn.2257 (2009).

21. Ratajczak, P., Wozniak, A. \& Nowakowska, E. Animal models of schizophrenia: Developmental preparation in rats. Acta Neurobiol. Exp. (Wars) 73, 472-484 (2013).

22. Hoffman, A. C. Z. Territoriality in Drosophila melanogaster as a conditional strategy. Animal Behav. 40, 526-537 (1990).

23. Wang, L., Dankert, H., Perona, P. \& Anderson, D. J. A common genetic target for environmental and heritable influences on aggressiveness in Drosophila. Proc. Natl. Acad. Sci. USA 105, 5657-5663. https://doi.org/10.1073/pnas.0801327105 (2008).

24. Bentzur, A. et al. Early life experience shapes male behavior and social networks in Drosophila. Curr. Biol. https://doi.org/10. 1016/j.cub.2020.10.060 (2020).

25. Ganguly-Fitzgerald, I., Donlea, J. \& Shaw, P. J. Waking experience affects sleep need in Drosophila. Science 313, 1775-1781. https:// doi.org/10.1126/science.1130408 (2006). 
26. Panova, A. et al. Group rearing leads to long-term changes in locomotor activity of Drosophila males. Open J. Animal Sci. 03, 31-35. https://doi.org/10.4236/ojas.2013.34A2004 (2013).

27. Eddison, M. et al. arouser reveals a role for synapse number in the regulation of ethanol sensitivity. Neuron 70, 979-990. https:// doi.org/10.1016/j.neuron.2011.03.030 (2011).

28. Kim, W. J., Jan, L. Y. \& Jan, Y. N. Contribution of visual and circadian neural circuits to memory for prolonged mating induced by rivals. Nat. Neurosci. 15, 876-883. https://doi.org/10.1038/nn.3104 (2012).

29. Heisenberg, M., Heusipp, M. \& Wanke, C. Structural plasticity in the Drosophila brain. J. Neurosci. 15, 1951-1960 (1995).

30. Technau, G. M. Fiber number in the mushroom bodies of adult Drosophila melanogaster depends on age, sex and experience. J. Neurogenet. 21, 183-196. https://doi.org/10.1080/01677060701695359 (2007).

31. Donlea, J. M., Ramanan, N. \& Shaw, P. J. Use-dependent plasticity in clock neurons regulates sleep need in Drosophila. Science 324, 105-108. https://doi.org/10.1126/science.1166657 (2009).

32. Kent, C. \& Agrawal, P. Regulation of social stress and neural degeneration by activity-regulated genes and epigenetic mechanisms in dopaminergic neurons. Mol. Neurobiol. https://doi.org/10.1007/s12035-020-02037-7 (2020).

33. Ueda, A. \& Wu, C. F. Effects of social isolation on neuromuscular excitability and aggressive behaviors in Drosophila: altered responses by Hk and gsts1, two mutations implicated in redox regulation. J. Neurogenet. 23, 378-394. https://doi.org/10.3109/ 01677060903063026 (2009).

34. Zelikowsky, M. et al. The neuropeptide Tac2 controls a distributed brain state induced by chronic social isolation stress. Cell 173, 1265-1279.e1219. https://doi.org/10.1016/j.cell.2018.03.037 (2018).

35. Kennedy, A. et al. Internal states and behavioral decision-making: Toward an integration of emotion and cognition. Cold Spring Harb. Symp. Quant. Biol. 79, 199-210. https://doi.org/10.1101/sqb.2014.79.024984 (2014).

36. Edwards, A. C., Zwarts, L., Yamamoto, A., Callaerts, P. \& Mackay, T. F. Mutations in many genes affect aggressive behavior in Drosophila melanogaster. BMC Biol. 7, 29. https://doi.org/10.1186/1741-7007-7-29 (2009).

37. Edwards, A. C. \& Mackay, T. F. Quantitative trait loci for aggressive behavior in Drosophila melanogaster. Genetics 182, 889-897. https://doi.org/10.1534/genetics.109.101691 (2009).

38. Edwards, A. C., Rollmann, S. M., Morgan, T. J. \& Mackay, T. F. Quantitative genomics of aggressive behavior in Drosophila melanogaster. PLoS Genet. 2, e154. https://doi.org/10.1371/journal.pgen.0020154 (2006).

39. Pielage, J., Bulat, V., Zuchero, J. B., Fetter, R. D. \& Davis, G. W. Hts/Adducin controls synaptic elaboration and elimination. Neuron 69, 1114-1131. https://doi.org/10.1016/j.neuron.2011.02.007 (2011).

40. Bednarek, E. \& Caroni, P. Beta-adducin is required for stable assembly of new synapses and improved memory upon environmental enrichment. Neuron 69, 1132-1146. https://doi.org/10.1016/j.neuron.2011.02.034 (2011).

41. Tada, H. et al. Neonatal isolation augments social dominance by altering actin dynamics in the medial prefrontal cortex. Proc. Natl. Acad. Sci. USA 113, E7097-E7105. https://doi.org/10.1073/pnas.1606351113 (2016).

42. Yan, Z., Kim, E., Datta, D., Lewis, D. A. \& Soderling, S. H. Synaptic actin dysregulation, a convergent mechanism of mental disorders?. J. Neurosci. 36, 11411-11417. https://doi.org/10.1523/JNEUROSCI.2360-16.2016 (2016).

43. Simon, J. C. \& Dickinson, M. H. A new chamber for studying the behavior of Drosophila. PLoS ONE 5, e8793. https://doi.org/10. 1371/journal.pone.0008793 (2010).

44. Kabra, M., Robie, A. A., Rivera-Alba, M., Branson, S. \& Branson, K. JAABA: Interactive machine learning for automatic annotation of animal behavior. Nat. Methods 10, 64-67. https://doi.org/10.1038/nmeth.2281 (2013).

45. Matsuoka, Y., Li, X. \& Bennett, V. Adducin: Structure, function and regulation. Cell Mol. Life Sci. 57, 884-895. https://doi.org/10. 1007/PL00000731 (2000).

46. Ohler, S., Hakeda-Suzuki, S. \& Suzuki, T. Hts, the Drosophila homologue of Adducin, physically interacts with the transmembrane receptor Golden goal to guide photoreceptor axons. Dev. Dyn. 240, 135-148. https://doi.org/10.1002/dvdy.22515 (2011).

47. Kanamori, T. et al. Compartmentalized calcium transients trigger dendrite pruning in Drosophila sensory neurons. Science 340, 1475-1478. https://doi.org/10.1126/science.1234879 (2013).

48. Sarov, M. et al. A genome-wide resource for the analysis of protein localisation in Drosophila. Elife 5, e12068. https://doi.org/10. 7554/eLife.12068 (2016).

49. Nassel, D. R., Liu, Y. \& Luo, J. Insulin/IGF signaling and its regulation in Drosophila. Gen. Comp. Endocrinol. 221, 255-266. https:// doi.org/10.1016/j.ygcen.2014.11.021 (2015).

50. Brent, A. E. \& Rajan, A. Insulin and Leptin/Upd2 exert opposing influences on synapse number in fat-sensing neurons. Cell Metab. https://doi.org/10.1016/j.cmet.2020.08.017 (2020).

51. Meschi, E., Leopold, P. \& Delanoue, R. An EGF-responsive neural circuit couples insulin secretion with nutrition in Drosophila. Dev. Cell 48, 76-86.e75. https://doi.org/10.1016/j.devcel.2018.11.029 (2019).

52. Zhan, Y. P., Liu, L. \& Zhu, Y. Taotie neurons regulate appetite in Drosophila. Nat. Commun. 7, 13633. https://doi.org/10.1038/ ncomms13633 (2016).

53. Agrawal, P., Kao, D., Chung, P. \& Looger, L. L. The neuropeptide Drosulfakinin regulates social isolation-induced aggression in Drosophila. J. Exp. Biol. https://doi.org/10.1242/jeb.207407 (2020).

54. Söderberg, J. A., Carlsson, M. A. \& Nässel, D. R. Insulin-producing cells in the drosophila brain also express satiety-inducing cholecystokinin-like peptide. Drosulfakinin. Front. Endocrinol. (Lausanne) 3, 109. https://doi.org/10.3389/fendo.2012.00109 (2012).

55. Wu, F. et al. A neuropeptide regulates fighting behavior in Drosophila melanogaster. Elife https://doi.org/10.7554/eLife.54229 (2020).

56. Bennett, V., Gardner, K. \& Steiner, J. P. Brain adducin: A protein kinase C substrate that may mediate site-directed assembly at the spectrin-actin junction. J. Biol. Chem. 263, 5860-5869 (1988).

57. Kiang, K. M. \& Leung, G. K. A review on adducin from functional to pathological mechanisms: Future direction in cancer. Biomed. Res. Int. 2018, 3465929. https://doi.org/10.1155/2018/3465929 (2018).

58. Leite, S. C. et al. The actin-binding protein alpha-adducin is required for maintaining axon diameter. Cell Rep. 15, 490-498. https:// doi.org/10.1016/j.celrep.2016.03.047 (2016).

59. Krieger, C., Wang, S. J., Yoo, S. H. \& Harden, N. Adducin at the neuromuscular junction in amyotrophic lateral sclerosis: hanging on for dear life. Front. Cell Neurosci. 10, 11. https://doi.org/10.3389/fncel.2016.00011 (2016).

60. Engmann, O. et al. DARPP-32 interaction with adducin may mediate rapid environmental effects on striatal neurons. Nat. Commun. 6, 10099. https://doi.org/10.1038/ncomms10099 (2015).

61. Lim, R. S., Eyjólfsdóttir, E., Shin, E., Perona, P. \& Anderson, D. J. How food controls aggression in Drosophila. PLoS ONE 9 , e105626. https://doi.org/10.1371/journal.pone.0105626 (2014).

62. Simon, A. F. et al. A simple assay to study social behavior in Drosophila: Measurement of social space within a group. Genes Brain Behav. 11, 243-252. https://doi.org/10.1111/j.1601-183X.2011.00740.x (2012).

63. Charney, A. W. et al. Evidence for genetic heterogeneity between clinical subtypes of bipolar disorder. Transl. Psychiatry 7, e993. https://doi.org/10.1038/tp.2016.242 (2017).

64. Bosia, M. et al. ADDing a piece to the puzzle of cognition in schizophrenia. Eur. J. Med. Genet. 59, 26-31. https://doi.org/10.1016/j. ejmg.2015.12.012 (2016).

65. Morozova, T. V., Goldman, D., Mackay, T. F. \& Anholt, R. R. The genetic basis of alcoholism: Multiple phenotypes, many genes, complex networks. Genome Biol. 13, 239. https://doi.org/10.1186/gb-2012-13-2-239 (2012). 
66. Gilligan, D. M., Sarid, R. \& Weese, J. Adducin in platelets: Activation-induced phosphorylation by PKC and proteolysis by calpain. Blood 99, 2418-2426. https://doi.org/10.1182/blood.v99.7.2418 (2002).

67. Rajgopal, Y. \& Vemuri, M. C. Calpain activation and alpha-spectrin cleavage in rat brain by ethanol. Neurosci. Lett. 321, 187-191. https://doi.org/10.1016/s0304-3940(02)00063-0 (2002).

68. Metwally, E., Zhao, G., Li, W., Wang, Q. \& Zhang, Y. Q. Calcium-activated calpain specifically cleaves glutamate receptor IIA but not IIB at the drosophila neuromuscular junction. J. Neurosci. 39, 2776-2791. https://doi.org/10.1523/JNEUROSCI.2213-17.2019 (2019).

69. Fontenele, M. et al. Calpain A modulates Toll responses by limited Cactus/IkappaB proteolysis. Mol. Biol. Cell 24, $2966-2980$. https://doi.org/10.1091/mbc.E13-02-0113 (2013).

70. Sreenan, S. K. et al. Calpains play a role in insulin secretion and action. Diabetes 50, 2013-2020. https://doi.org/10.2337/diabetes. 50.9.2013 (2001)

71. Okamoto, N. \& Nishimura, T. Signaling from glia and cholinergic neurons controls nutrient-dependent production of an insulinlike peptide for drosophila body growth. Dev. Cell 35, 295-310. https://doi.org/10.1016/j.devcel.2015.10.003 (2015).

72. Cong, X. et al. Regulation of sleep by insulin-like peptide system in drosophila melanogaster. Sleep 38, 1075-1083. https://doi.org/ 10.5665/sleep.4816 (2015).

73. Sudhakar, S. R. et al. Insulin signalling elicits hunger-induced feeding in Drosophila. Dev Biol 459, 87-99. https://doi.org/10.1016/j. ydbio.2019.11.013 (2020).

74. Ja, W. W. et al. Prandiology of drosophila and the CAFE assay. Proc. Natl. Acad. Sci. USA 104, 8253-8256. https://doi.org/10.1073/ pnas.0702726104 (2007).

75. Koto, A., Mersch, D., Hollis, B. \& Keller, L. Social isolation causes mortality by disrupting energy homeostasis in ants. Behav. Ecol. Sociobiol. 69, 583-591. https://doi.org/10.1007/s00265-014-1869-6 (2015).

76. Tomova, L. et al. Acute social isolation evokes midbrain craving responses similar to hunger. Nat. Neurosci. 23, 1597-1605. https:// doi.org/10.1038/s41593-020-00742-z (2020).

77. Consortium, C.-D. G. o. t. P. G. Genomic relationships, novel loci, and pleiotropic mechanisms across eight psychiatric disorders. Cell 179, 1469-1482.e1411. https://doi.org/10.1016/j.cell.2019.11.020 (2019).

78. O'Kane, C. J. Drosophila as a model organism for the study of neuropsychiatric disorders. Curr. Top Behav. Neurosci. 7, 37-60. https://doi.org/10.1007/7854_2010_110(2011).

79. van Alphen, B. \& van Swinderen, B. Drosophila strategies to study psychiatric disorders. Brain Res. Bull. 92, 1-11. https://doi.org/ 10.1016/j.brainresbull.2011.09.007 (2013).

80. Colombani, J. et al. A nutrient sensor mechanism controls Drosophila growth. Cell 114, 739-749. https://doi.org/10.1016/s00928674(03)00713-x (2003).

81. Hoopfer, E. D., Jung, Y., Inagaki, H. K., Rubin, G. M. \& Anderson, D. J. P1 interneurons promote a persistent internal state that enhances inter-male aggression in Drosophila. Elife https://doi.org/10.7554/eLife.11346 (2015).

82. Dankert, H., Wang, L., Hoopfer, E. D., Anderson, D. J. \& Perona, P. Automated monitoring and analysis of social behavior in Drosophila. Nat. Methods 6, 297-303. https://doi.org/10.1038/nmeth.1310 (2009).

83. Wolf, F. W., Rodan, A. R., Tsai, L. T. \& Heberlein, U. High-resolution analysis of ethanol-induced locomotor stimulation in Drosophila. J. Neurosci. 22, 11035-11044 (2002).

84. Corl, A. B. et al. Happyhour, a Ste20 family kinase, implicates EGFR signaling in ethanol-induced behaviors. Cell 137, 949-960. https://doi.org/10.1016/j.cell.2009.03.020 (2009).

85. Robie, A. A. et al. Mapping the neural substrates of behavior. Cell 170, 393-406.e328. https://doi.org/10.1016/j.cell.2017.06.032 (2017).

86. Kabra, M., Robie, A. A., Rivera-Alba, M., Branson, S. \& Branson, K. JAABA: Interactive machine learning for automatic annotation of animal behavior. Nat. Meth. 10, 64-67. https://doi.org/10.1038/nmeth.2281 (2013).

\section{Acknowledgements}

This work was conducted in and funded by the HHMI laboratory of Prof. Ulrike Heberlein and I am indebted to her for letting me run with this idea. Dr. Alice Robie, Austin Edwards and Dr. Kristin Branson for help with the fly bowl. Phoung Chung for help with dissections and immunocytochemistry, Xiaorong Zhang for inverse PCR, Dr. Nan Chen with DAM assays, and the fly core and fly kitchen for general assistance. The Drosophila community at Janelia and especially past members of the Heberlein lab for stimulating discussions. The comments of Dr. Anita Devineni were most helpful in the preparation of this paper.

\section{Author contributions}

M.E. designed and performed the experiments, wrote the manuscript, and prepared the figures.

\section{Competing interests}

The author declares no competing interests.

\section{Additional information}

Supplementary Information The online version contains supplementary material available at https://doi.org/ 10.1038/s41598-021-96871-x.

Correspondence and requests for materials should be addressed to M.E.

Reprints and permissions information is available at www.nature.com/reprints.

Publisher's note Springer Nature remains neutral with regard to jurisdictional claims in published maps and institutional affiliations. 
(c) (i) Open Access This article is licensed under a Creative Commons Attribution 4.0 International cc) License, which permits use, sharing, adaptation, distribution and reproduction in any medium or format, as long as you give appropriate credit to the original author(s) and the source, provide a link to the Creative Commons licence, and indicate if changes were made. The images or other third party material in this article are included in the article's Creative Commons licence, unless indicated otherwise in a credit line to the material. If material is not included in the article's Creative Commons licence and your intended use is not permitted by statutory regulation or exceeds the permitted use, you will need to obtain permission directly from the copyright holder. To view a copy of this licence, visit http://creativecommons.org/licenses/by/4.0/.

(C) The Author(s) 2021 